\title{
Rapid analysis of knowledge, attitudes and practices towards substance addiction across different target groups in Abu Dhabi City, United Arab Emirates
}

Hesham Elarabi ${ }^{1}$, Fatima Al Hamedi ${ }^{2}$, Susan Salas ${ }^{3}$, Shamil Wanigaratne ${ }^{4}$

${ }^{I}$ National Rehabilitation Center, Head, Department of Health Education and Training, Abu Dhabi, UAE; 'National Rehabilitation Center, Clinical Psychologist, Department of Clinical Psychology, Kings College, London; ${ }^{3}$ Salas Consulting; ${ }^{4}$ Clinical Psychologist, Senior Consultant, Director General's Office, National Rehabilitation Center, Abu Dhabi, UAE Corresponding author Hesham Elarabi-Email: Hisham.alarabi@nrc.ae

\section{Abstract \\ Objectives}

To understand the interaction of socio-demographic factors and knowledge, attitudes and practices of the general public, parents and youth in Abu Dhabi, in order to develop culturally sensitive substance use prevention programmes.

\section{Methods}

The data was gathered via convenience sampling using questionnaires developed for each target group during a road show on addiction prevention.

\section{Results}

Perceived primary cause of substance addiction is weakened/breakdown of religiosity, as rated by $34.2 \%$ of the sample, and it is influenced by sociodemographic characteristics such as nationality, gender and education. Independent of socio-demographic characteristics, addicts were perceived by over $50 \%$ of the population as 'victims' and less than $6 \%$ perceived drug addicts as criminals. Majority of the respondents evaluated their parenting skills as 'good'.

Fifteen percent of youth and adolescents considered experimenting with alcohol and hashish and perception of harm level is associated with tendency to experiment alcohol or hashish.

\section{Conclusion}

Religiosity seems to be perceived as a protective factor for substance use. Socio-demographic factors have an impact on attitudes and perceptions towards substance use. 


\section{Introduction}

Knowledge based studies are the building blocks of addiction research, while studying drug use initiation and prevention contributes to the development of drug education programmes. ${ }^{1}$

Perception of harm level affects tendency to use substances, e.g. tobacco. ${ }^{2}$ In return, risk denial was identified as an opposing factor to risk perception. ${ }^{3}$

The interaction between genetics and environment was studied in a Danish twin study. Twin females to alcohol dependent mothers were brought up in different environments, one described as religious and the other as nonreligious. While the incidence of alcoholism in the non-religious environment was $40 \%$ the religious arm reported zero alcoholism. ${ }^{4}$

Addiction research is lacking in the Arab world despite increasing problematic substance use. ${ }^{5}$ Body of literature on addiction in the Gulf States is small and descriptive in nature. Only two studies on substance use attitudes and knowledge were retrieved. "In the Kingdom of Saudi Arabia (KSA), 740 students were questioned about their knowledge on substance abuse. The study suggested that knowledge and awareness about the risks of drug addiction was limited among Saudi Arabian nationals and their religion, Islam, played a major role in the prevention and treatment of substance addiction". 6 The second study included 1001 Kuwaiti participants in the state of Kuwait. ${ }^{7}$ The study focused in the participants' attitudes towards substance use using a 30 item questionnaire which was culturally adapted to suit the participants. This study used extensive sampling representing different sectors of the community (undergraduates, secondary school students of opposite genders, hospital and primary care clinic staff). Results suggested that the Kuwaiti community (a 100\% Muslim community), perceived drug and alcohol use as sinful. However, they considered addiction treatment as 'should be offered'. Such attitude was graded as 'enlightened by the authors'. It was described as being a non-conventional accepting attitude towards substance use. This conclusion is remarkable given that the study was conducted over 21 years ago.

Factors predisposing to substance use were reported by Al Kandari and colleagues $^{8}$ as excessive unsupervised free time, peer pressure, accessibility and psychological problems. In the United Arab Emirates (UAE), rapid social changes and weakened religiosity were speculated as precedents to drug use. ${ }^{9,10}$ This has been supported in an editorial review, 'the enemy within' describing the challenges encountered by Gulf States with drug addiction.$^{11}$ Drug addiction was described as a "silent epidemic" that is under-diagnosed and under-treated. This review however did not cover alcohol and other drugs of abuse, e.g. prescription medicine. 
In the UAE, seven studies were retrieved from 1994 to 2001. Five were community based and household studies describing mental health and psychiatric characteristics including substance use, and one targeting the criminal justice population. All studies sampled populations with similar ethnic and religious backgrounds. Overall, studies did not employ rigorous sampling. In summary, no study evaluated substance knowledge or attitudes across different populations in the Arab world except that of Bilal and colleagues. $^{12}$

The UAE may represent a challenging model for substance use response and prevention. Lying on the South East location of the Arabian Peninsula and on the major drug trafficking routes, the UAE is a member state of the Gulf Cooperation Council (GCC). The United Arab Emirates enjoys a diverse culture with over $79 \%$ of its population made up of expatriates representing 180 different nationalities.

A study that explores knowledge, attitude and behaviour towards drug and alcohol use would be a stepping stone to curb the drug menace.

\section{Methods}

\section{Research Design}

Cross sectional study using an anonymous self-administered questionnaire administered via non probability convenience sampling. The objective was to,

1 To identify the correlation between socio-demographic variables (age, nationality, social status, education level), perceptions, attitudes and patterns of behaviour

2 Confirm or reject whether the public perception about causes of addiction may be due to a non religious background

3 To identify the perception and attitudes of youths towards alcohol use

4 To study the correlation of socio-demographic variables with a tendency to substance use

5 To study the correlation of smoking among youth and the tendency to get addicted to substance use 
Research Tool Development: Three self-reported questionnaires were developed for i) general public, ii) youth and adolescents and iii) population influencing the high risk population, i.e. parents and guardians. All questionnaires were drafted by a team of experts in Arabic and translated to English which were later translated to Arabic. ("Public Knowledge, Attitudes and Behaviours towards addiction") HE001 A/E; Elarabi et al. 2008)

The questionnaire aimed to gather public knowledge, attitudes and practices towards the problem of substance addiction. The questions were grouped under knowledge, attitudes and practices as follows:

Knowledge: Questions were covered by Perceived disease size (Q.1); Perceived susceptibility (Q.2, Q.3); Knowledge on addiction (Q.4, 8, 9, 10)

Attitudes: Attitudes towards substance users (Q.5), Perceived barriers to seeking treatment.

\section{Behaviours}

Dealing with a recovering addiction patient (Q.6), Action to refer individuals (Q.11)

The "Assessment of protective parenting skills and practices" (HE002 A/E; Elarabi et al 2008) composed of 13 questions. This questionnaire was able to measure basic parental skills that are not culturally-oriented. Content was adopted from the parents' brochure issued by the National Institute of Drug Abuse, USA. Responses were set at three levels "Always" "Sometimes" and "Seldom". A numerical scoring system was developed for each level with a score of ' 2 ' for "Always", a score of ' 1 ' for "Sometimes" and ' 0 ' for "Seldom". The maximum allowable score is 26 divided across the three categories. Scores from 1 to 11 graded parenting skills at a level of "concern" requiring additional reinforcement, scores of 12 to 18 graded parenting skills as "average" and scores above 18 reflected "good" parenting communication skills and practices.

The "Brief assessment of youth knowledge and attitudes and practices on substances" (HE003 A/E; Elarabi et al 2008) composed of seven questions. This tool covered i) perceived harm of alcohol and recreational drugs, ii) tendency to experiment and use alcohol, iii) knowledge level of drug hazards iv) preferred prevention tools and modalities. It does not inquire on personal use of substances. Socio-demographic section was deferred to the end of the questionnaire. 


\section{Tool reliability}

"Test-retest" reliability was conducted with a random sample of 10 individuals for every questionnaire. The reported reliability coefficient for questionnaires HE001, HE002 and HE003 are 0.82, 0.89, 0.91 respectively.

Sampling, sample size and survey administration

Participants were gathered using non probability convenience sampling during a seven day addiction prevention road show at the largest shopping mall in Abu Dhabi in 2008. Given the study design, sample size was the number of respondents that could be reached.

The road show had multimedia showcasing on harmful effects of drugs, a counselling corner, a station for educational materials and giveaways. Additionally, the road show anchored a large stage for the live performance of an educational play targeting children aged 5-10 years. Participants visiting the road show were requested to complete the questionnaires before receiving an in-depth education on substance use prevention. It is important to note that the show case attracted primarily Arabic speakers since the majority of the activities were in the Arabic language.

Questionnaires were distributed by facilitators. Participants completing Questionnaire HE001 were then asked to complete the questionnaire HE002, if they had children.

Questionnaires were coded and entered on an SPSS spreadsheet. No sampling was done from the gathered questionnaires and all collected data forms were entered in SPSS. 


\section{Results}

A. Comparative demographics of respondents data from questionnaires are summarized in Table 1.

\begin{tabular}{|c|c|c|c|}
\hline Questionnaire & HE001 & HE002 & HE003 \\
\hline $\begin{array}{l}\text { Number of } \\
\text { participants }\end{array}$ & $n=1531$ & 582 & 533 \\
\hline Response rate & $95 \%$ & $72 \%$ & $96 \%$ \\
\hline $\begin{array}{l}\text { Mean or median } \\
\text { age of population } \\
\text { (SD) }\end{array}$ & 28.36 & 28.82 & 19.48 \\
\hline $\begin{array}{l}\text { Education level } \\
\qquad \begin{aligned} \text { A. University } \\
\text { B. High } \\
\text { School } \\
\text { C. Primary } \\
\text { School }\end{aligned}\end{array}$ & $\begin{array}{l}\text { A. } 61 \% \\
\text { B. } 30.3 \%\end{array}$ & $\begin{array}{l}\text { A. } 70.1 \% \\
\text { B. } 24.6 \%\end{array}$ & $\begin{array}{l}\text { A. } 52.3 \% \\
\text { B. } 37.7 \%\end{array}$ \\
\hline Male/female ratio & $2.2 / 1$ & $2.3 / 1$ & $3 / 1$ \\
\hline $\begin{array}{l}\text { Marital status } \\
\qquad \begin{array}{l}\text { A. Single } \\
\text { B. Married } \\
\text { C. Divorced }\end{array}\end{array}$ & $\begin{array}{l}\text { A. } 44.9 \% \\
\text { B. } 52.8 \% \\
\text { C. } 2.3 \% \\
\end{array}$ & A. $100 \%$ & $\begin{array}{l}\text { A. } 66.2 \% \\
\text { B. } 32.3 \%\end{array}$ \\
\hline UAE Nationals & $52.5 \%$ & $32.5 \%$ & $69.1 \%$ \\
\hline $\begin{array}{l}\text { Area of residence } \\
\qquad \begin{aligned} \text { A. Capital City } \\
\text { B. Eastern } \\
\text { Region } \\
\text { (Suburban) }\end{aligned} \\
\text { C. } \begin{array}{l}\text { Western } \\
\text { Region } \\
\text { (Rural) }\end{array}\end{array}$ & $52.5 \%$ & $39.2 \%$ & \\
\hline Smoking & NA & NA & $32.6 \%$ \\
\hline
\end{tabular}


Table 1. Comparative demographics of respondents' data

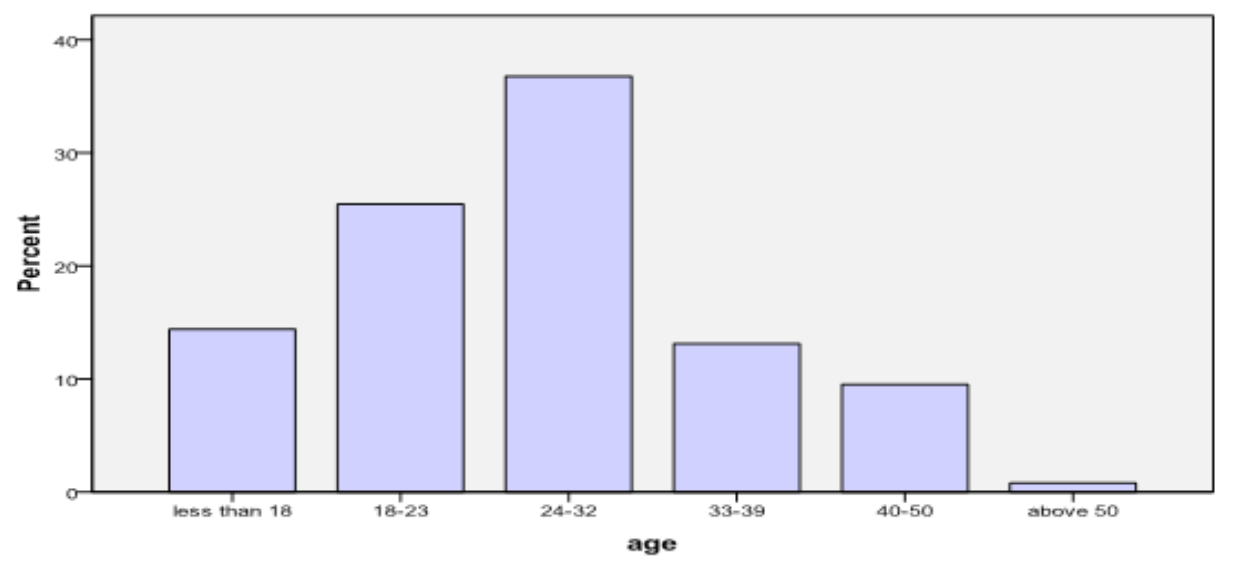

Figure1. Age distribution

B. Descriptive results

\section{Public knowledge}

Over half of the respondents perceived the size of substance addiction problem as 'moderate to large' $(63.2 \%, \mathrm{n}=947)$ compared to $17.9 \%(\mathrm{n}=268)$ who perceived it as 'small' and $18.9 \%(\mathrm{n}=283)$ did not know the problem size in the UAE (Chart 2). Majority (77.9\%) perceived youths to be at real risk to substance use and addiction compared to $22.1 \%$ who did not know or perceived youth not to be at risk. The need for addiction treatment facilities was felt by $93.2 \%$ of the respondents.

'Weakened/breakdown of religiosity' was ranked as the primary reason for substance use by $34.2 \%$ followed by 'peer pressure' $(28.3 \%)$ and 'free time' $(26.6 \%)$. The major barrier for treatment seeking is 'social stigma' as reported by $46.5 \%$ of the respondents, followed by 'fear of prosecution' by $31.7 \%$. In the same connection, $34.8 \%$ of the respondents perceived actions taken towards clients seeking treatment voluntarily as 'prosecutory' versus $65.2 \%$ who reported that no legal actions are taken against voluntary patients. No distinct trend was seen regarding the knowledge on treatment outcomes of substance use and other chronic diseases. Finally, knowledge on drugs is equivocal between 'good' and 'excellent' on one end, and 'fair' and 'inadequate' at the other. 


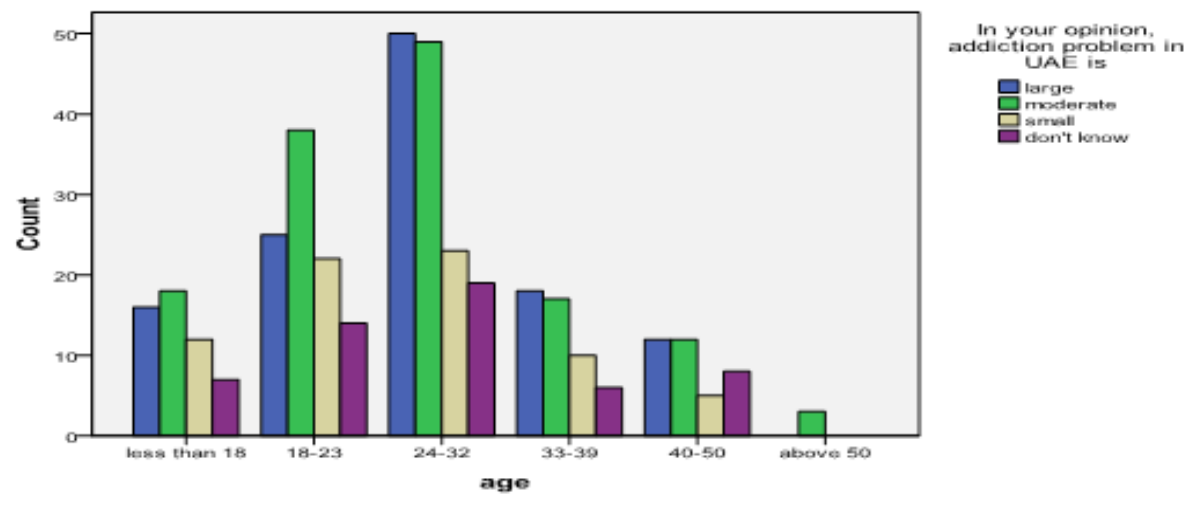

Figure 2 Perceived size of addiction problem

\section{Public attitudes}

Over half of the respondents (50.3\%) perceived addicts as 'victims', and $33.0 \%$ as patients while only $6 \%$ of the respondents perceived addicts as 'criminals'. Nevertheless, almost $11 \%$ (10.7\%) perceived addicts as individuals with deviant behaviour or misconduct.

\section{Public behaviour}

Majority of the respondents (65.8\%) had no issues dealing with patients in recovery. Almost all respondents confirmed that they would recommend treatment to a patient $(n=95 \%)$.

\section{Parenting practices (Questionnaire HE 002)}

Majority of the respondents ( $\mathrm{n}=496,82.5 \%$ ) evaluated their parental practices as good. Almost three quarters reported 'always' to all questions, except for questions 9 and 11. (For question 9 "Do you spare constant time to spend with your children", the response was $62 \%$ and for question 11 "Do you teach your children how to manage/ deal with stress", the response was $57.3 \%$ ).

V. Knowledge and attitudes of adolescents and youths (Questionnaire HE 003)

More than three-quarters $(76.1 \%)$ perceived 'alcohol as having similar harm to illicit drugs' and even a larger percentage perceived cannabis as addictive (83.7\%). However, $16.2 \%$ of the respondents considered experimenting with alcohol and $11 \%$ considered experimenting with drugs. 
Almost three-quarters of the respondents $(74.5 \%)$ confirmed their knowledge about the risk and harm of drugs, while $25.5 \%$ were not aware of the risks and harm.

Youth understood the risks and harm of using drugs (44.2\%) and religious or spiritual factors $(44.5 \%)$ as effective tools in substance use.

Correlation between socio-demographic variables such as age, nationality, social status, area of residence (urban vs suburban), education level and knowledge, attitudes and patterns of behaviour:

A one way analysis of variants (ANOVA) was applied and it was found that socio-demographic characteristics significantly impacted perceiving religiosity, peer pressure and free time as causes of addiction $F(5, \infty)=0.058, p<0.05$. A small effect $(\eta 2=0.058)$ of perceiving 'weakened/breakdown of religiosity' as a cause of addiction is due to nationality, gender and education. The impact of different education levels, but not other characteristics on perceiving 'free time' as a cause of addiction has a small effect ( $\eta 2=0.014)$.

On the other hand, other than age, ANOVA was insignificant for the role of socio-demographic characteristics on attitudes towards substance users $F(3, \infty)=1.495$. ANOVA was only significant for age $(2, \infty)=6.323, p<0.05$. A very small effect $(\eta 2=0.009)$ in dealing with recovered addicts was found due to age with $0.9 \%$ variability.

Did the public perception support breakdown/weakened religiosity as a cause of substance addiction (HE 001)?

A one sample t-test was done and it was found that respondents did perceive weakened/breakdown in religiosity as a significant factor in developing addiction $t(\infty)=59.22, p<0.05$. This finding rejects the research hypothesis that public perception has changed due to rapid social changes.

Does the level of knowledge impact patterns of behaviour across different age groups?

A chi-square analysis was applied to the relationship between the perception of susceptibility to substance adopting and adopting 'good' parenting practices, and no effect was found $k 2(4, n=580)=$ 6.344 .

A chi-square analysis was applied to the relationship between perceiving alcohol's harm being similar to illicit drugs and the tendency to experiment with alcohol. The result was statistically 
significant $2(1, \mathrm{n}=730)=13.451, \mathrm{p}<0.01$. Respondents who perceived alcohol as having similar harmful effects to illicit drugs did not consider experimenting with alcohol.

A chi-square analysis was applied to the relationship between the addictive potential of hashish and the tendency to experiment with hashish. The result was significant i $2(1, \mathrm{n}=730)=20.292 \mathrm{p}<0.01$. Respondents who perceived hashish as addictive did not consider experimenting with it.

A chi-square analysis was applied to the relationship between attitudes towards 'addicts' and the level of difficulty dealing with the recovered addict. The result was significant $k 2(6, n=1380)=32.274$ $\mathrm{p}<0.01$. Respondents who perceived drug addicts as 'victims', had a higher tendency not to experience problems dealing with a recovered addict.

Does youth in the UAE consider substance use a kind of experiment? If yes, is there a significant correlation with socio-demographic characteristics?

A one-sample $t$ test was performed to see if youth in the UAE significantly consider experimenting with alcohol or hashish. The test found that respondents did significantly consider using hashish or alcohol $\mathrm{t}(\infty)=11.56 .22$ (alcohol), $\mathrm{p}<0.05 ; \mathrm{t}(\infty)=9.00$ (hashish), $\mathrm{p}<0.05$. Socio-demographic characteristics did not have any significant effect on the consideration to experiment with either alcohol or hashish.

\section{Discussion}

The UAE is reported to have over $79 \%$ of its population as non-national expatriates. Rapid changes in social attitudes and breakdown in religiosity were speculated as potential predisposing factors to substance use by researchers over 17 years ago. ${ }^{9}$

In the Gulf countries drug use is described as "taboo". ". Substance use can result in imprisonment up to four years. ${ }^{12}$ Thus, it was surprising that substance addiction problem perceived by $30.6 \%$ as large and $32.6 \%$ as moderate, as there is no published data on the scale of the problem in the country. One possible explanation is that news on drug seizures appearing in the media. Another reason is overestimation of substance use problems. ${ }^{13}$ Consequently, a need for substance dependent treatment is perceived. This need for treatment, however, did not seem to drive perceiving addicts as patients in this study.

Though the study was not designed to measure social stigma, it provides some insight into the problem. Drug addicts were widely perceived as victims. 
Victimization is correlated with and predisposes substance use, mental health disorders and neuro-anatomical brain changes. ${ }^{14,15}$ There is increasing literature on substance use and increased vulnerability to victimization. ${ }^{16,17}$ The definition of 'what a victim is' to the study population is not clear. Despite the absence of any diagnostic connotation, a victim is not perceived to be responsible for his status. However, respondents with the 'victim' attitude identified weakened religiosity as a major cause of substance dependence.

Accelerated social changes in the country have not deferred public perception away from the importance of religiosity in substance use prevention. Youths in this study reported religion as a major factor in addiction prevention.

Over $15 \%$ of youths responding to this questionnaire considered experimenting with alcohol. This is a 'red flag' as drinking is not a social norm among the majority of the respondents. However, those who perceived alcohol as harmful, by rating alcohol harm similar to illicit drugs were less likely to consider its experimentation. Similarly, participants perceiving cannabis as addictive were less likely to experiment it. This supports the protective nature of not using substance and knowledge about the risks of substance use.

\section{Strengths and limitations:}

Strengths: Coverage of different target population in addition to good response rates.

Limitations: Questionnaire HE002 had lower response rates. It also lacked a critical field on the age of respondents' children. Parents with children less than five years of age would by default know how their children spend their free time when compared with parents whose children were in the age group 15-18 years. Majority of the respondents were young parents, below the age of 40 years, and their children were below adolescence.

No robust sampling was done. As a result, the study sample was not representative of the entire population of the United Arab Emirates, e.g. majority of the respondents were citizens of the UAE whereas within the UAE population, these citizens make up less than $20 \%$ of the overall population. This limit provided inferences about differences across cultural backgrounds. Yet, it can also be viewed as a strong point, as it tests how diverse sociodemographic characteristics in the UAE have influenced its citizens.

\section{Recommendations for future research}

Our main recommendation is to conduct a comprehensive situation assessment study on the prevalence of substance abuse, its pattern and burden of disease. This could include a component to identify risk and protective factors using age specific structured tools. Consider evaluation of religiosity using age specific structured tools which are considered as risk factors for substance 
use.

Declaration of interest: The authors report no conflicts of interest. The authors alone are responsible for the content and writing of the paper.

Acknowledgement: The authors acknowledge the guidance received from Professor Kim Wolff.

\section{References:}

1. Lennox RD, Cecchini MA. The NARCONON drug education curriculum for high school students: a non-randomized, controlled prevention trial. Substance Abuse Treatment Prevention Policy. 2008; 3:8

2. Lam TH, Chung SF. Tobacco Advertisements: One of the strongest risk factors for smoking in Hong Kong students. Am J of Prev Med.1998;14(3): $217-23$

3. Devos T, Dubois-Arber F, Gervasoni JP. Secondary prevention of drug abuse: problems and examples. Therrapeutische Umschau. 1997; 54(8):46872

4. Koopmans, Slutske, van Baal, Boomsma DI. The influence of religion on alcohol use initiation: Evidence for genotype $\mathrm{X}$ environment interaction. Behav Genet.1999; 29(6):445-53

5. World Drug Report, 2011.www.unodc.org/documents/ WDR_2007WDR_2011 eng_web.pdf

6. Al-Subaie, A. S., Al-Hajjaj, M. S. Awareness and knowledge of Saudi university students about drug dependence. Saudi Med J.1995; 16:326-329

7. Bilal Am, Makhawi B, Al Fayex G, Shaltout A.F. Attitudes of a sector of the Arab-Muslim Population in Kuwait towards alcohol and drug misuse: An objective appraisal. Drug Alcohol Depend.1990

8. Al-Kandari F. H., Yacoub K., Omu, F. Initiation factors for substance abuse. J Adv Nurs.2001; 34: 78-85

9. Amin Y., Hamdi E., Ghubash, R. Substance abuse consultation rates: Experience from private practice in Dubai. The Arab Journal of Psychiatry.1996; 7: 133-139

10. Younis, Y. O., \& Saad, A. G. A profile of alcohol and drug misusers in an Arab community. Addiction.1995; 90: 1683-1684

11. Al-harthi A., Al-Adawi S. Enemy within? The silent epidemic of substance dependency in GCC countries. SQU Journal of Scientific Research: Medical Sciences.2002;Vol.4 
12. Federal UAE GAZET 1995

13. Riou Franca L, Dautzenberg B, Falissard B, Reynaud M. Peer substance use overestimation among French university students: A cross-sectional survey. BMC Public Health.2010; 29;10:169

14. Arellano, C. Child maltreatment and substance use: A review of the literature. Subst Use Misuse.1996;31: 927-935

15. Kilpatrick, D., Acierno, R., Saunders, B., Resnick, H., \& Best, C. Risk factors for adolescent substance abuse and dependence: Data from a national sample. J Consult Clin Psychol. 2000;68: 19-30

16. Kessler, R., Sonnega, A., Bromet, E., Hughes, M, \& Nelson, C. Posttraumatic stress disorder in the National Comorbidity Survey. Arch of Gen Psychiatry.1995;52: 1048-1060

17. Kilpatrick, D., Acierno, R., Resnick, H., Saunders, B., \& Best, C. A 2-year longitudinal analysis of the relationship between violent assault and substance use in women. J Consult Clin Psychol.1997; 65:834-847 